\title{
Adult Dental Health Survey 2009: relationships between dental attendance patterns, oral health behaviour and the current barriers to dental care
}

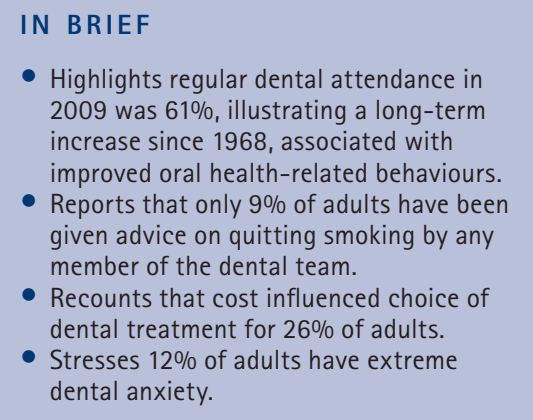

- Highlights regular dental attendance in 2009 was $61 \%$, illustrating a long-term increase since 1968, associated with improved oral health-related behaviours.

- Reports that only $9 \%$ of adults have been given advice on quitting smoking by any member of the dental team.

dental treatment for $26 \%$ of adults.

dental anxiety.

\author{
K. B. Hill, ${ }^{1}$ B. Chadwick, ${ }^{2}$ R. Freeman, ${ }^{3}$ I. O'Sullivan ${ }^{4}$ and J. J. Murray ${ }^{5}$
}

The importance of understanding barriers to dental attendance of adults in the UK was acknowledged in the first Adult Dental Health Survey in 1968 and has been investigated in all subsequent ADH surveys. In 1968, approximately 40\% of dentate adults said they attended for a regular check-up; by 2009 this was 61\%. Attendance patterns were associated with greater frequency of toothbrushing, use of additional dental hygiene products, lower plaque and calculus levels. Just under three-fifths of adults said they had tried to make an NHS dental appointment in the previous five years. The vast majority (92\%) successfully received and attended an appointment, while a further 1\% received an appointment but did not attend. The remaining 7\% of adults were unable to make an appointment with an NHS dentist. The majority of adults were positive about their last visit to the dentist, with $80 \%$ of adults giving no negative feedback about their last dentist visit. Cost and anxiety were important barriers to care. Twenty-six percent of adults said the type of treatment they had opted for in the past had been affected by the cost and 19\% said they had delayed dental treatment for the same reason. The 2009 survey data demonstrated a relationship between dental anxiety and dental attendance. Adults with extreme dental anxiety were more likely to attend only when they had trouble with their teeth (22\%) than for a regular check-up.

\section{INTRODUCTION}

This is the third in a series of papers following the publication of the 2009 Adult Dental Health Survey and covers the attitudes and barriers to dental care, including dental attendance patterns and barriers to attendance.

Regular attendance for a routine oral health examination has been encouraged for the maintenance of oral health and has gained an increased importance with the publication of the evidence-based guideline on dental recall. ${ }^{1}$ The importance of understanding attendance patterns together with barriers to dental attendance

\footnotetext{
"Senior Lecturer in Dental Public Health and Behavioural Science, College of Medical and Dental Sciences, School of Dentistry, St Chad's Queensway, Birmingham, B4 6NN; ${ }^{2}$ Professor Paediatric Dentistry, Paediatric Dentistry Unit, School of Dentistry, Cardiff University, Heath Park, Cardiff, CF14 4XY; ${ }^{3}$ Professor of Dental Public Health, Director of the Oral Health and Health Research Programme, Dental Health Services Research Unit, University of Dundee, Dundee, DD2 4BF; ${ }^{4}$ Assistant Divisional Director, Social Survey Division, ONS, Cardiff Road, Newport, NP10 8XG; ${ }^{5}$ Emeritus Professor, School of Dental Sciences, Newcastle University, NE2 4BW

${ }^{*}$ Correspondence to: Dr Kirsty Hill

Email: k.b.hill@bham.ac.uk; Tel: 01214665488
}

\section{Refereed Paper}

Accepted 4 October 2012

DOI: 10.1038/sj.bdj.2012.1176

${ }^{\circledR}$ British Dental Journal 2013; 214: 25-32 of adults in the UK was acknowledged in the first Adult Dental Health Survey (ADHS) back in $1968^{2}$ and data on attendance have been collected in all subsequent surveys in the series. A key finding in the first ADHS was that those attending the dentist for a regular dental examination had large differences in oral health-related attitudes and behaviours as well as the dental treatment received when compared to those adults who attended only when experiencing pain or having trouble.

Our understanding of the reasons for non-attendance or 'barriers' to attending for regular dental care have changed in the intervening years ${ }^{3-5}$ with the contribution from Cohen ${ }^{6}$ highlighting the role of dental anxiety, costs of dental treatment, lack of access to dental services together with the individual's perception of need as of central importance. Therefore, the barriers that patients experience in relation to accessing dental care may arise as a result of social structural conditions for example, socioeconomic factors, ${ }^{7}$ life experiences such as unemployment and/or psychosocial factors such as dental anxiety. ${ }^{6}$ Questions on psycho-social factors were first included in the 1988 ADHS. Dental anxiety is now considered to be one of the most important barriers to patients accessing dental care ${ }^{4,8}$ and in the 2009 survey the Modified Dental Anxiety Scale (MDAS) ${ }^{9}$ was included together with questions concerning costs of dental treatment, perception of need and lack of accessibility.

Since tailored oral health advice has been acknowledged as the primary consideration in the promotion of oral health self-care, data on oral health-related preventive behaviours such as toothbrushing advice and toothpaste use have been in the ADHS since its inception. In ADHS 2009 additional risks to oral health, such as smoking and the advice received from dental teams, were included for the first time. Epidemiological studies have linked participant dental anxiety status to be positively associated with an increase in decayed and missing teeth and negatively associated with filled teeth, ${ }^{10,11}$ but associations with oral health-related preventive behaviours such as tooth brushing with a fluoride toothpaste are as yet not clearly understood. The aims of this paper are, therefore, two-fold. Firstly, to explore the relationships between dental attendance patterns, dental anxiety and 
oral health-related preventive and risk behaviours; and secondly, to examine the barriers to dental care.

\section{METHODS}

The sample size for the survey was 13,400 households, including: 1,150 in each English Strategic Health Authority and Wales, and 750 households in Northern Ireland. A total of 11,380 individuals were interviewed, and 6,469 dentate adults were clinically examined. Scotland did not take part in this survey so we do not have data for the UK. The data reported here are related mostly to the interview, although data on plaque and calculus and most of the clinical data are reported in papers one and two of the series..$^{12,13}$ In most cases the data for the three countries are combined for simplicity, but where they have been split by country it should be clearly indicated.

The interview explored a number of issues including attendance, barriers, attitudes, service questions, quality of life scales and dental anxiety. In the 2009 survey dental anxiety was assessed by the Modified Dental Anxiety Scale (MDAS) ${ }^{9}$ a modified version of Corah's Dental Anxiety Scale ${ }^{14}$ and included a question assessing anticipatory dental anxiety associated with local anaesthesia as well as four other scenarios about which respondents had to report the extent of their dental anxiety. A five point response format ranging from one (not anxious) to five (extremely anxious) was used to assess the level of dental anxiety. The lowest possible score is five, indicating low dental anxiety. The maximum possible score is 25, with scores of 19 and above indicating extreme dental anxiety, which may be indicative of dental phobia. During the dental examination the presence of plaque and calculus were recorded.

\section{RESULTS}

\section{Dental attendance patterns in UK adults 1968-2009}

In 1968, approximately $40 \%$ of dentate adults in England and Wales said they attended for a regular check-up. In 1978, $43 \%$ of dentate adults reported attending for a regular check-up and by 1998 this had increased to 59\%. In 2009 almost two thirds (61\%) of dentate adults said the usual reason they attend the dentist is for a regular check-up. A further 10\% said

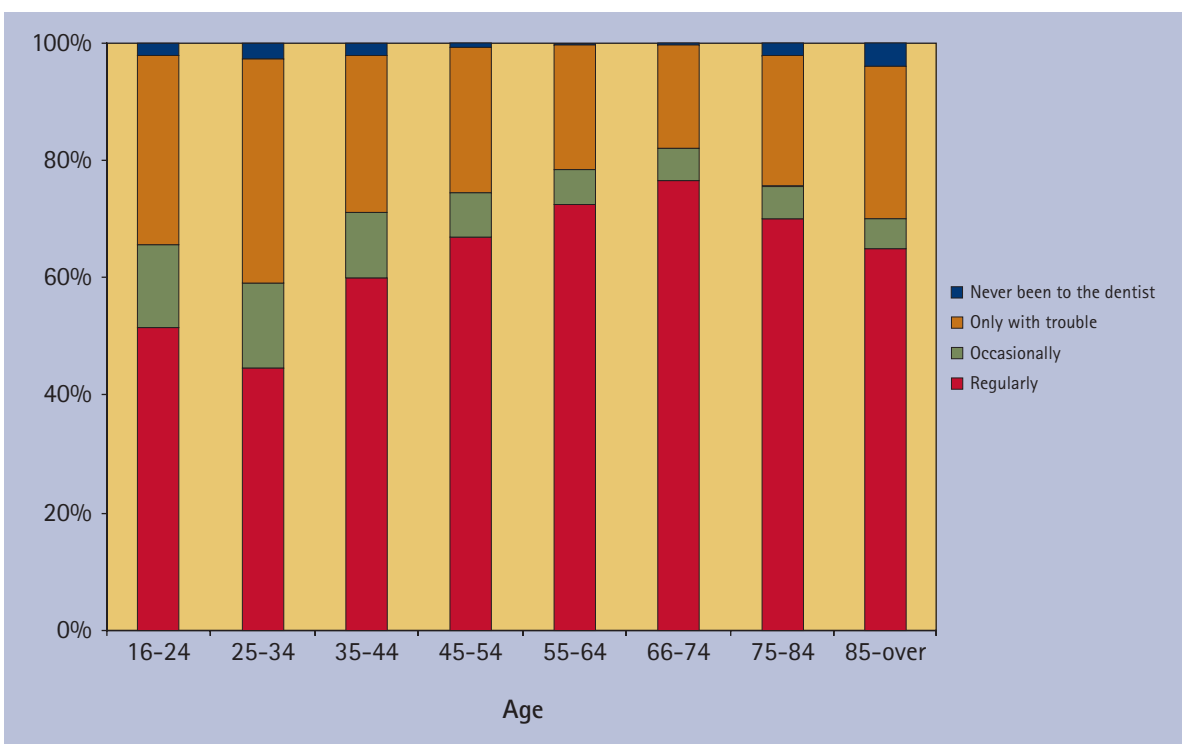

Fig. 1 Dental attendance patterns by age (England, Wales and Northern Ireland combined). Reproduced from O'Sullivan I, (ed). Adult Dental Health Survey 2009 - Summary report and thematic series. Leeds: Health and Social Care Information Centre, 2010. With the permission of the Health and Social Care Information Centre. All rights reserved

Table 1 Association of dental attendance patterns with other variables (England, Wales and Northern Ireland combined)

\begin{tabular}{|l|l|l|l|l|}
\hline Variable & $\begin{array}{l}\text { Regular } \\
\text { attendance (\%) }\end{array}$ & $\begin{array}{l}\text { Occasional } \\
\text { attendance (\%) }\end{array}$ & $\begin{array}{l}\text { Trouble } \\
\text { only (\%) }\end{array}$ & $\begin{array}{l}\text { Never } \\
\text { attends (\%) }\end{array}$ \\
\hline Frequency of cleaning
\end{tabular}

\begin{tabular}{|l|l|l|l|l|l}
\hline Twice or more a day & 80 & 74 & 65 & 53 \\
\hline Once a day & 19 & 23 & 30 & 37 \\
\hline Less than once & 1 & 2 & 4 & 6 \\
\hline Never & 0 & 1 & 1 & 4 \\
\hline Use of hygiene products & 37 & 43 & 53 & 76 \\
\hline Only toothbrush and toothpaste & 37 & 56 & 47 & 24 \\
\hline Other products & 63 & 32 & 31 & 19 \\
\hline Uses mouthwash & 31 & 25 & 16 & 7 \\
\hline Uses electric toothbrush & 31 & 78 & 70 & - \\
\hline Advice on brushing & 82 & 67 & 76 & 88 \\
\hline Received advice & 61 & 65 & 79 & 86 \\
\hline Visible plaque & 64 & \multicolumn{2}{|l}{} \\
\hline
\end{tabular}

that they attend for an occasional checkup, $27 \%$ said that they attend only when having trouble and 2\% said they never attend the dentist (Fig. 1). Importantly, attendance patterns were associated with other aspects of oral health-related preventive behaviours, including frequency of toothbrushing, use of additional dental hygiene products, plaque levels and presence of calculus and lower levels of anxiety (Table 1). As can be seen, regular attendance is associated with improved reported oral health-related preventive behaviours and lower visible plaque and calculus levels.

\section{Oral health-related behaviours of UK adults in 2009}

The present and previous surveys have reported that the majority of dentate adults claim to brush their teeth twice a day (Table 2). 


\begin{tabular}{|c|c|c|c|c|c|c|c|c|c|}
\hline \multirow{2}{*}{$\begin{array}{l}\text { Reported frequency } \\
\text { of tooth cleaning }\end{array}$} & \multicolumn{3}{|c|}{ England } & \multicolumn{3}{|c|}{ Wales } & \multicolumn{3}{|c|}{ Northern Ireland } \\
\hline & 1988 & 1998 & 2009 & 1988 & 1998 & 2009 & 1988 & 1998 & 2009 \\
\hline Twice a day or more often & $67 \%$ & $74 \%$ & $75 \%$ & $64 \%$ & $74 \%$ & $71 \%$ & $69 \%$ & $72 \%$ & $75 \%$ \\
\hline Once a day & $27 \%$ & $22 \%$ & $23 \%$ & $27 \%$ & $21 \%$ & $25 \%$ & $22 \%$ & $22 \%$ & $22 \%$ \\
\hline Less than once a day & $5 \%$ & $4 \%$ & $2 \%$ & $8 \%$ & $4 \%$ & $3 \%$ & $7 \%$ & $6 \%$ & $3 \%$ \\
\hline Never & $1 \%$ & $0 \%$ & $1 \%$ & $1 \%$ & $0 \%$ & 15 & $1 \%$ & $1 \%$ & $0 \%$ \\
\hline Unweighted base & 3,016 & 3,010 & 9,000 & 622 & 682 & 880 & 558 & 636 & 660 \\
\hline Weighted base $(=000 \mathrm{~s})$ & & & 39,296 & & & 2,181 & & & 1,292 \\
\hline
\end{tabular}

Reproduced from 0'Sullivan I, (ed). Adult Dental Health Survey 2009 - Summary report and thematic series. Leeds: Health and Social Care Information Centre, 2010. With the permission of the Health and Social Care Information Centre. All rights reserved

NB: Unweighted base is the actual of number of people interviewed; weighted base is an estimate against population values (per 100,000)

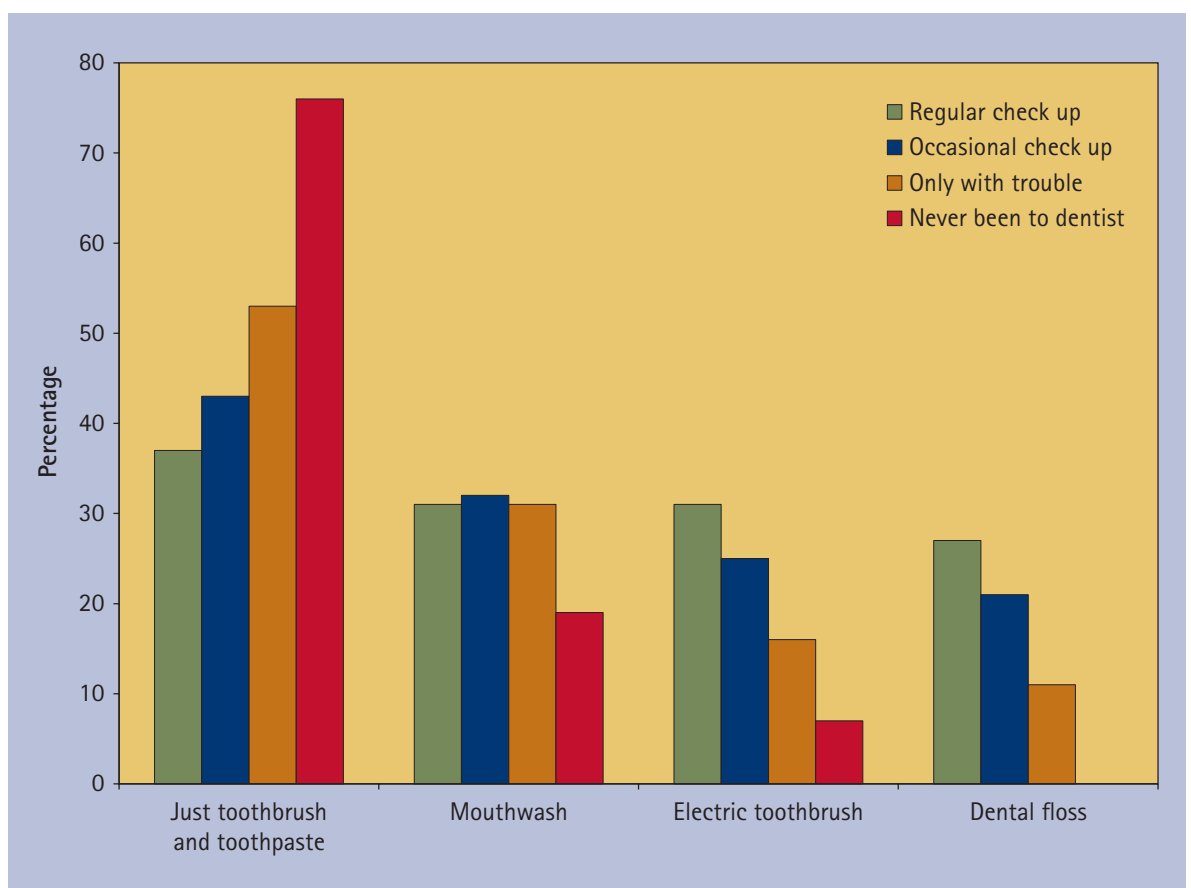

Fig. 2 The use of dental hygiene products by reason for dental attendance, 2009 (England, Wales and Northern Ireland combined). Reproduced from O'Sullivan I, (ed). Adult Dental Health Survey 2009 - Summary report and thematic series. Leeds: Health and Social Care Information Centre, 2010. With the permission of the Health and Social Care Information Centre. All rights reserved

Dentate adults who said that they brushed their teeth were asked whether, in addition to a manual toothbrush and toothpaste, they used any other methods of maintaining oral hygiene. The use of other products was reported by 58\% of adults, with mouthwash (31\%), electric toothbrushes (26\%), and dental floss (21\%) the most frequently mentioned. More women than men (61\% against 53\%) said they used something other than a normal toothbrush. Additional methods were most popular among adults aged 35-64 years. Regular dental attendees were more likely to report using other
Presence of plaque and calculus in UK adults (2009)

Two thirds of dentate adults had visible plaque on at least one tooth. The average number of teeth with plaque was 6.0, almost one quarter of all standing teeth. Sixty-four percent of dentate adults who cleaned their teeth at least twice a day had visible plaque compared with $94 \%$ of those who cleaned their teeth less than once a day or never. Men were more likely to have plaque than women (71\% compared with $61 \%$ ) and they also had a higher proportion of affected teeth (27\% versus 20\%). Dentate adults who said they attend the dentist for a regular check-up were less likely to have visible plaque (61\%) than those who reported only attending the dentist in trouble (76\%).

Calculus was present in at least one sextant of the mouth in $68 \%$ of adults and on average 1.8 sextants were affected. There was a strong association between the prevalence of calculus and usual reason for dental attendance. While 64\% of adults who attended for a regular check-up had calculus, this rose to $79 \%$ of those adults who only attended the dentist in trouble. Sixty-seven percent of adults who reported brushing their teeth twice a day or more had calculus compared with 89\% of those who said that they brushed their teeth less than once a day or never. Current smokers were also more likely than those who used to smoke or had never smoked to have calculus, 79\% compared with $65 \%$ and $66 \%$ respectively.

While twice-daily brushing is now a fact of life for three quarters of the population, the high levels of both plaque and calculus in those who brush twice daily suggests there is still room for improving the efficacy of brushing.

\section{Smoking behaviour and smoking cessation advice for UK adults in 2009}

For the first time in the ADHS series, questions on smoking behaviour were included and asked of all adults, including young adults aged 16-18 years. These questions were included as there is clear evidence that smoking is associated with poor periodontal health ${ }^{15}$ and smoking cessation guidelines recommend that all health professionals, including members of the dental team, should ask about smoking annually and advise smokers to quit. The smoking 
questions used were the Government harmonised questions on smoking that have been used in many other Government sponsored health surveys. All respondents, whether dentate or edentate, were asked whether they currently smoked and if not, whether they had ever smoked: 22\% of all adults said that they currently smoked and marginally more edentate adults said they were smokers compared with dentate adults, 24\% compared with $22 \%$.

In order to assess whether dental health teams are regularly contributing to smoking cessation programmes, all dentate adults who had visited a dentist in the two years before being interviewed were asked if any member of the dental team had given them advice on giving up smoking at their most recent visit. A small minority of adults (9\%) reported having been given advice on quitting smoking, with 35\% of adults stating they had never smoked. While the remaining 57\% said that they had not received any advice on smoking cessation, it is likely that these individuals will have included many ex-smokers (and therefore do not need any advice) and individuals who the dental team already know are not (and may never have been) smokers.

It is also important for adults who are edentate to receive smoking cessation advice, given the association between smoking and oral cancer. All edentate adults who had been to the dentist in the two years before the interview were also asked if they had received any advice on stopping smoking from the dentist. As for dentate adults, a small proportion of adults (7\%) said that they had received smoking cessation advice, the vast majority (72\%) of adults with no teeth were not given any advice on smoking cessation, 22\% said they had never smoked.

Patient recall of smoking cessation advice seems low, suggesting either that the dental team is less confident discussing this aspect of care or that advice is not recalled for whatever reason. To some extent dentists are probably being selective about giving advice but it would be good to see all smokers who engage with dental practitioners receiving and recalling advice. Interestingly, $64 \%$ of regular attendees have no recall of being asked about diet, which one would think is an area dentists should be more comfortable with.

In conclusion, attendance for dental treatment on an ad hoc basis in this UK adult population was associated with poorer adherence with toothbrushing regimes, low usage of additional interdental cleaning aids and increased presence of plaque and calculus. Moreover, compared with those that accessed care on a regular basis, the participants who attended when in trouble had poorer recall of being provided with dental healthcare advice. Thus it is necessary to understand why a proportion of the UK adult population in 2009 continue to attend only when in trouble in order to promote oral health and reduce oral health inequalities.

\section{Access as a barrier to care in 2009: making an NHS appointment}

All adults who participated in the survey were asked if they had tried to make an NHS dental appointment in the last three years. No attempt was made to define what constituted an NHS appointment and the survey respondents were permitted to respond according to what they personally understood NHS dental care to be. There was no distinction made between primary and secondary care. The main reason why respondents were not guided towards a definition of what constitutes an NHS dental appointment was that any such definition would be immensely complicated to define in its entirety requiring issues such as dental charges and the provision of components provided on a private basis to be clarified.

Just under three fifths (58\%) of adults said that they had tried to make an NHS dental appointment in the previous three years; the remainder said they had not. In terms of the socio-demographic characteristics of the population, differences were observed between age-groups, sex and adults from different household socioeconomic classifications. Specifically, a smaller proportion of older adults (aged 85 and older) reported trying to make an NHS dental appointment than adults in all other age groups; 34\% of adults aged 85 and over said that they had tried to make an NHS dental appointment in the last three years compared with $64 \%$ of 45-54-years-olds and 57\% of adults aged 16-24 years. Women were more likely than men to have tried to make an NHS dental appointment in the last three years, $62 \%$ compared with 54\%; and a smaller proportion of adults from managerial and professional occupation households (56\%) than adults from intermediate occupation households (62\%) tried to make an NHS dental appointment.

Adults who said they attended the dentist regularly were the most likely to say they had tried to make an NHS dental appointment in the last three years (70\% compared with $63 \%$ of occasional attendees and 38\% of those who said they only went to the dentist when they had trouble with their teeth). It is noteworthy that $30 \%$ of adults who had been to the dentist in the year before being interviewed for the survey had not attempted to get an NHS appointment. This suggests that many adults now receive dental care from what they regard as a non-NHS source and is in line with the current survey which reported that $27 \%$ had their last course of treatment with a private dentist.

The experience of those adults who indicated that they had tried to make an NHS dental appointment in the three years before being interviewed on the survey was assessed. The vast majority of these adults (92\%) successfully received and attended an appointment while a further $1 \%$ of adults received an appointment but did not attend. The remaining $7 \%$ of adults were unable to make an appointment with an NHS dentist. The inability to arrange an NHS dental appointment varied by age with a general pattern of younger adults being more likely to fail to get an appointment; for example 10\% of adults aged 25-34 years were unable to get an NHS dental appointment compared with $4 \%$ of 65-74-year-olds and 5\% of 75-84-yearolds. The inability to get an appointment with an NHS dentist did not vary by other socio-demographic characteristics.

\section{Costs as a barrier to dental treatment}

Since the inception of the NHS in 1948, the NHS dental service has undergone frequent changes in administration. The 1998 survey referred to the changes in the previous 10 years. When the data for the 1988 and 1998 were compared, there had been a three-fold increase in the proportion of dentate adults reporting that their treatment was carried out privately: from 6\% from 1988 to 19\% in 1998. In 2009, paid for NHS dental care was the most commonly reported type of dental care received, with $45 \%$ of dentate adults receiving their last completed course of treatment in this way. Private dental care was reported by $27 \%$ (a 


\section{Table 3 Type of dental care received during last completed course of treatment by characteristics of dentate adults}

Dentate adults

\begin{tabular}{|l|l|l|l|l|l|l|l|l|l|}
\hline $\begin{array}{l}\text { Characteristics } \\
\text { of dentate } \\
\text { adults }\end{array}$ & $\begin{array}{l}\text { Private } \\
(\%)\end{array}$ & $\begin{array}{l}\text { Paid for NHS } \\
\text { dental care } \\
(\%)\end{array}$ & $\begin{array}{l}\text { Free NHS } \\
\text { dental care } \\
(\%)\end{array}$ & $\begin{array}{l}\text { NHS and } \\
\text { private care } \\
(\%)\end{array}$ & $\begin{array}{l}\text { Other } \\
(\%)\end{array}$ & $\begin{array}{l}\text { Not sure } \\
(\%)\end{array}$ & $\begin{array}{l}\text { Total paid for or } \\
\text { free NHS dental } \\
\text { care (\%) }\end{array}$ & $\begin{array}{l}\text { Unweighted } \\
\text { base }\end{array}$ & $\begin{array}{l}\text { Weighted } \\
\text { base (000s) }\end{array}$ \\
\hline All & 27 & 45 & 25 & 1 & 1 & 1 & 71 & 10,090 & 40,255 \\
\hline
\end{tabular}

Age

\begin{tabular}{|l|l|l|l|l|l|l|l|l|l|}
\hline $16-24$ & 17 & 28 & 53 & 0 & 1 & 1 & 81 & 960 & 6,085 \\
\hline $25-34$ & 21 & 47 & 29 & 1 & 1 & 2 & 77 & 1,320 & 6,192 \\
\hline $35-44$ & 26 & 48 & 22 & 1 & 1 & 1 & 71 & 1,950 & 7,854 \\
\hline $45-54$ & 28 & 51 & 18 & 1 & 1 & 1 & 70 & 1,970 & 7,178 \\
\hline $55-64$ & 33 & 50 & 14 & 1 & 1 & 1 & 64 & 1,810 & 6,173 \\
\hline $65-74$ & 33 & 49 & 16 & 1 & 0 & 0 & 65 & 1,280 & 3,936 \\
\hline $75-84$ & 38 & 42 & 17 & 1 & 0 & 2 & 59 & 680 & 2,378 \\
\hline 85 or over & 41 & 40 & 15 & 1 & 2 & 2 & 56 & 120 & 460 \\
\hline $5 e x$ & & & & & & & & &
\end{tabular}

Sex

\begin{tabular}{|l|l|l|l|l|l|l|l|l|l|}
\hline Male & 27 & 47 & 23 & 1 & 1 & 1 & 70 & 4,490 & 19,552 \\
\hline Female & 27 & 44 & 27 & 1 & 0 & 1 & 71 & 5,590 & 20,703 \\
\hline
\end{tabular}

\section{Country}

\begin{tabular}{|l|l|l|l|l|l|l|l|l|l|}
\hline England & 27 & 46 & 24 & 1 & 1 & 1 & 70 & 8,590 & 36,924 \\
\hline Wales & 29 & 37 & 33 & 0 & 0 & 1 & 70 & 870 & 2,131 \\
\hline Northern Ireland & 16 & 52 & 29 & 1 & 1 & 2 & 81 & 630 & 1,200 \\
\hline
\end{tabular}

English Strategic Health Authority

\begin{tabular}{|c|c|c|c|c|c|c|c|c|c|}
\hline North East & 18 & 50 & 29 & 1 & 1 & 1 & 80 & 860 & 1,824 \\
\hline North West & 22 & 50 & 26 & 0 & 1 & 1 & 76 & 880 & 5,113 \\
\hline $\begin{array}{l}\text { Yorkshire \&t } \\
\text { The Humber }\end{array}$ & 19 & 46 & 32 & 1 & 1 & 1 & 79 & 910 & 3,818 \\
\hline East Midlands & 24 & 47 & 27 & 1 & 0 & 0 & 74 & 980 & 3,057 \\
\hline West Midlands & 24 & 48 & 27 & 0 & 0 & 1 & 75 & 760 & 3,758 \\
\hline East of England & 26 & 49 & 23 & 1 & 1 & 1 & 72 & 930 & 4,103 \\
\hline London & 31 & 39 & 26 & 3 & 0 & 0 & 65 & 630 & 5,105 \\
\hline South East Coast & 36 & 40 & 20 & 1 & 1 & 1 & 61 & 830 & 3,232 \\
\hline South Central & 40 & 42 & 14 & 2 & 1 & 1 & 56 & 890 & 2,981 \\
\hline South West & 32 & 45 & 21 & 1 & 1 & 1 & 66 & 930 & 3,935 \\
\hline
\end{tabular}

Socio-economic classification of household ${ }^{+}$

\begin{tabular}{l|l|l|l|l|l|l|l|l}
\hline $\begin{array}{l}\text { Managerial and } \\
\text { professional } \\
\text { occupations }\end{array}$ & 35 & 48 & 13 & 1 & 1 & 1 & 15,143 & 3,760 \\
\hline $\begin{array}{l}\text { Intermediate } \\
\text { occupations }\end{array}$ & 27 & 46 & 25 & 1 & 1 & 0 & 1 & 71 \\
\hline $\begin{array}{l}\text { Routine and } \\
\text { manual } \\
\text { operations }\end{array}$ & 19 & 42 & 37 & 1,227 & 1 & 79 \\
\hline
\end{tabular}

Reproduced from O'Sullivan I, (ed). Adult Dental Health Survey 2009 - Summary report and thematic series. Leeds: Health and Social Care Information Centre, 2010. With the permission of the Health and Social Care Information Centre. All rights reserved

*Excludes those who reported never attending the dentist or who had had their last course of treatment abroad.

tIncludes respondents who said they were treated in a dental hospital.

\#Excludes people in households where the household reference person was not interviewed. Respondents whose household reference person was a full-time student, in the Armed Forces, had an inadequately described occupation, had never worked or were long-term unemployed are not shown as separate categories but are included in the total. 
further increase from 1998) and free NHS care by 25\% of all dentate adults during their last completed course of treatment; very few respondents (1\%) reported receiving mixed NHS and private care. It is clear from these results that for the majority of dentate adults (71\%) the NHS is the primary provider of dental health services (Table 3).

Also, just over a quarter of adults (26\%) said that the type of dental treatment they opted to have in the past had been affected by the cost of this treatment and almost one fifth (19\%) said that they had delayed dental treatment for the same reason. These were not completely overlapping groups as indicated by the finding that $15 \%$ of adults indicated that both the type of treatment and timing of this treatment had been influenced by the cost in the past.

Although men and women were equally likely to say that the type of dental treatment they had in the past was influenced by cost, a greater proportion of women than men, 20\% compared with $17 \%$, said that they had delayed their dental treatment because of costs. Finally, people from all occupational classes reported that they had delayed treatment because of cost, but the differences were quite small; as might be expected in the context of lower income, a greater proportion of adults from routine and manual occupation households said that they had delayed dental treatment because of the cost $(20 \%)$ compared with adults from managerial and professional occupation households (17\%).

\section{Dental anxiety as a barrier to dental treatment}

Respondents were previously asked two questions relating to dental anxiety in the 1988 and 1998 national surveys. While the prevalence of dental anxiety fell between 1988 (60\%) and 1998 (32\%) the incidence of extreme dental fear remained constant in the order of $10 \%$ of the adult population and was associated with accessing dental treatment only when in pain. This suggested that a continuum of dental anxiety existed ranging from those who feel relaxed during dental treatment, to those who are dentally anxious but cope, through to those who are dentally phobic and avoid care. Dental anxiety therefore acts as a psychological barrier to seeking dental care and its association with oral health is of central importance. Just over half of adults

Table 4 Modified dental anxiety scale (England, Wales and Northern Ireland combined)

\begin{tabular}{|l|l|l|l|l|l|}
\hline All adults' & & Not anxious & $\begin{array}{l}\text { Slightly/fairly } \\
\text { anxious }\end{array}$ & $\begin{array}{l}\text { Very/extremely } \\
\text { anxious }\end{array}$ & \\
\hline Anxiety & $\%$ & 53 & 34 & 3 & \\
\hline In the waiting room & $\%$ & 50 & 35 & 15 & \\
\hline If tooth drilled & $\%$ & 28 & 42 & 30 & \\
\hline For scale and polish & $\%$ & 62 & 30 & 8 & 28 \\
\hline For injection & $\%$ & 30 & 41 & $19+$ & $\begin{array}{l}\text { Mean } \\
\text { score }\end{array}$ \\
\hline Total MDAS score & & $5-9$ & $10-18$ & 19 & 10.8 \\
\hline & $\%$ & 51 & 36 & 12 & 28 \\
\hline
\end{tabular}

Reproduced from 0'Sullivan I, (ed). Adult Dental Health Survey 2009 - Summary report and thematic series. Leeds: Health and Social Care Information Centre, 2010. With the permission of the Health and Social Care Information Centre. All rights reserved

'Adults who have never been to a dentist were not asked the MDAS questions

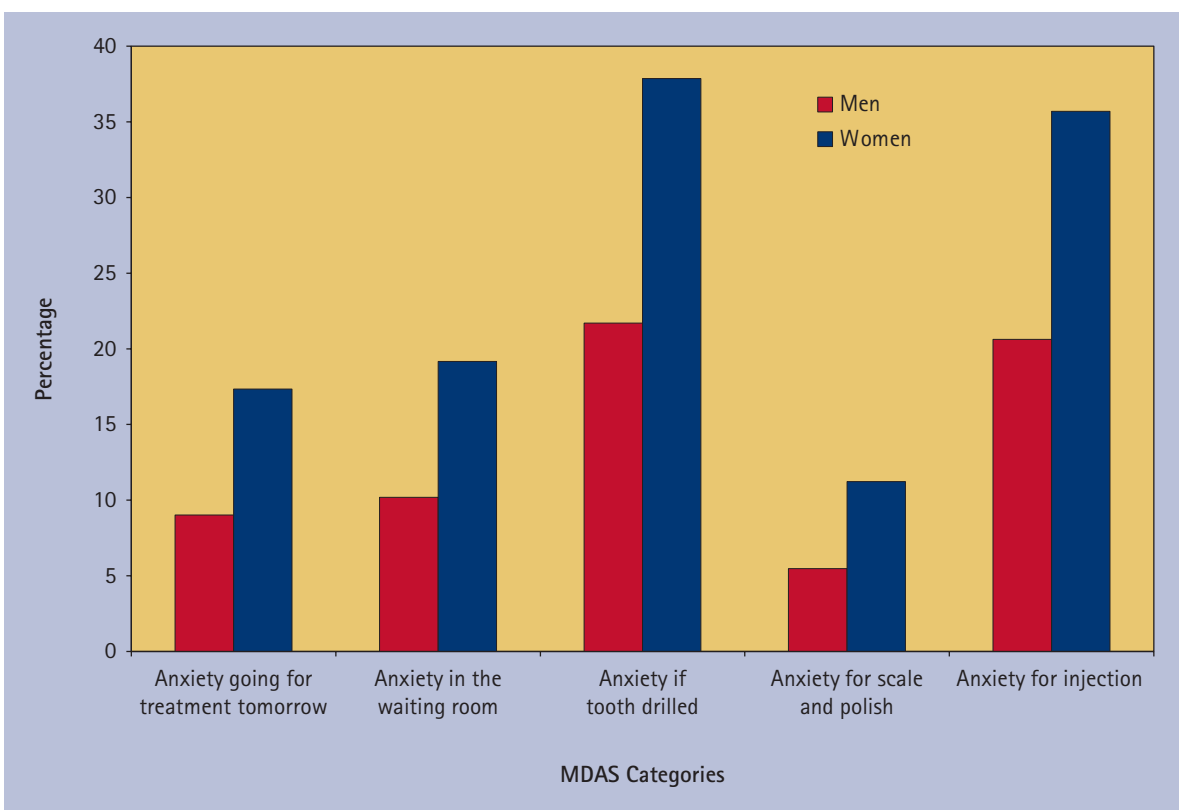

Fig. 3 Percentage reporting very/extremely anxious by sex (England, Wales and Northern Ireland combined). Reproduced from O'Sullivan I, (ed). Adult Dental Health Survey 2009 - Summary report and thematic series. Leeds: Health and Social Care Information Centre, 2010. With the permission of the Health and Social Care Information Centre. All rights reserved

(51\%) who had ever been to a dentist had an MDAS score of between 5 and 9, indicating low/no dental anxiety (Table 4).

The two items on the MDAS that elicited anxiety most often were both associated with receiving dental treatment; $30 \%$ of adults said that they would feel very or extremely anxious having a tooth drilled and 28\% reported similar levels of anxiety about having a local anaesthetic injection. A smaller proportion of adults were very or extremely anxious about sitting in the dentist's waiting room (15\%), about having to go to the dentist tomorrow (13\%) and having a scale and polish (8\%) (Fig. 3).
The 2009 survey data demonstrated a relationship between dental anxiety status and dental attendance. Adults with MDAS scores indicative of extreme dental anxiety were more likely to attend only when they have trouble with their teeth (22\%) than for a regular check-up (8\%).

\section{Oral health status of anxious patients}

There was a difference between people categorised on the basis of their experience of restorative dental treatment. For example, $6 \%$ of adults with 12 or more restored otherwise sound teeth had total MDAS scores of 19 or more compared with 14\% of adults 


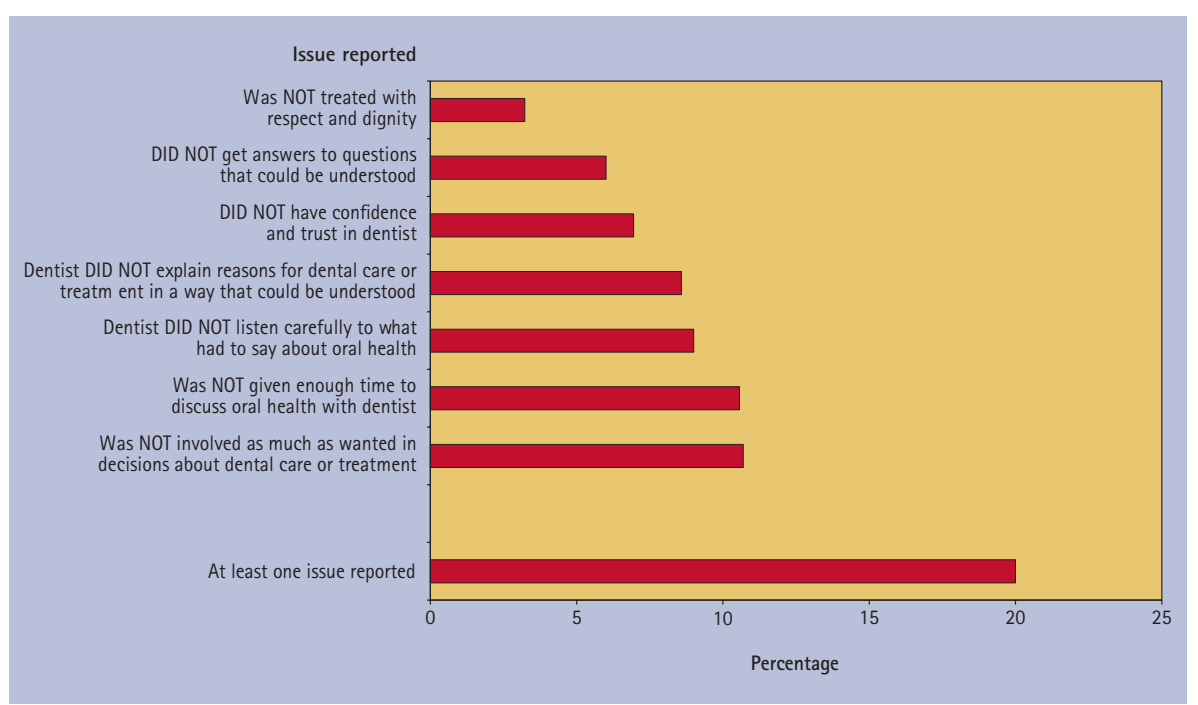

Fig. 4 Relationship with dentist at last visit (England, Wales and Northern Ireland combined). Reproduced from O'Sullivan I, (ed). Adult Dental Health Survey 2009 - Summary report and thematic series. Leeds: Health and Social Care Information Centre, 2010. With the permission of the Health and Social Care Information Centre. All rights reserved

Table 5 Rating of the dental practice (England, Wales and Northern Ireland combined)

\begin{tabular}{|c|c|}
\hline \multirow[t]{2}{*}{ All adults* } & England, Wales and Northern Ireland: 2009 \\
\hline & Percentage rating good/very good \\
\hline Length of time waiting for a routine appointment ${ }^{+}$ & 85 \\
\hline Length of time waiting for an urgent appointment ${ }^{+}$ & 87 \\
\hline Availability of evening/weekend appointments ${ }^{\dagger}$ & 53 \\
\hline Transport facilities and access & 77 \\
\hline Convenience of dental practice location & 80 \\
\hline Standard and quality of care & 90 \\
\hline Explanation of NHS changes ${ }^{+}$ & 56 \\
\hline Reputation of dentists & 79 \\
\hline $\begin{array}{l}\text { Reproduced from 0'Sullivan I, (ed). Adult Dental Health Survey } 2009 \\
\text { Information Centre, 2010. With the permission of the Health and So } \\
\text { "All adults who have attended the dentist in the last two years } \\
\text { tExcludes those who said it was not applicable } \\
\text { †Only applies to NHS patients }\end{array}$ & $\begin{array}{l}\text { ematic series. Leeds: Health and Social Care } \\
\text { tre. All rights reserved }\end{array}$ \\
\hline
\end{tabular}

with fewer than 12 restored otherwise sound teeth. It may be that the experience of having had many teeth restored is an indication of willingness to undergo restorative treatment and consequently, of lower dental anxiety, or that the experience of restorative treatment itself acts to reduce the likelihood of experiencing dental anxiety.

\section{Relationship with the dentist}

The ability of clinicians, including dentists, to communicate effectively with their patients is an essential skill. All adults who had visited the dentist (whether they attended an NHS or private dentist) were asked a series of questions about how they felt the dentist communicated with them at their last visit. The purpose of these questions was to determine the success of the interactions between patients and dentists and to investigate whether people felt involved in decisions about their oral health.

Encouragingly, the majority of adults were positive about their last visit to the dentist with $80 \%$ of adults giving no negative feedback about their last visit to the dentist (Fig. 4). However, 20\% of consultations were considered to be less than satisfactory in one way or another and it is important to determine what exactly about the dentist/patient interaction was problematic The two most commonly reported concerns related to not having been given enough time to discuss with the dentist and not being involved in decisions about dental care or treatment (11\%).

The survey collected self-reported dental health and there were clear differences between adults with good or bad indicators of oral health in terms of the dimensions used to assess the relationship between the patient and dentist. For example, a greater proportion of adults with bad or very bad self-reported dental health than adults with good or very good self-reported dental health, said that the dentist did not listen to them; felt that they were not given enough time to discuss their oral health; not involved in decisions about their oral health and had less confidence in the dentist.

\section{Rating the dental practice}

All adults who said that they had been to the dentist in the previous two years were asked to rate the dental practice they last attended on a number of domains including waiting times, explanation of NHS charges, access, quality of care and reputation of the dentist. Eighty-five percent of adults rated the practice they had attended most recently as good or very good for length of time waiting for routine appointments. Similarly, the vast majority of adults (87\%) indicated that their dental practice was good or very good in terms of the length of time waiting for an urgent appointment, however, just over half (53\%) said that their practice was good or very good at providing evening and/or weekend appointments. Adults were less positive about how well their dental practice explained NHS dental charges to them, $56 \%$ saying that their practice was good or very good at doing this. The standard of quality and care at the dental practice was also perceived by the vast majority of adults as being either good or very good (90\%), however, a slightly smaller proportion of adults indicated that the reputation of the dentists at their practice was good or very good (79\%). Nevertheless 93\% of adults said that they would go back to this practice in the future (Table 5).

\section{CONCLUSION}

The data presented here show that the demand for dental care has grown substantially over the last few decades, with a steadily increasing proportion of the 
population regarding themselves as regular attendees. With a growth in demand, access to NHS dental care has been a great concern in the United Kingdom since the mid-1990s and the findings presented in this report show that for the vast majority of patients NHS dentistry is reasonably accessible, although this finding is not universal. This growth in the use of services has been associated with improvements in cleaning and in the last decade there appears to have been a distinct shift towards a greater preventive ethos, including in some cases the introduction of smoking cessation. Dentists fared well in patient ratings, which should be a source of professional satisfaction, but this was not a universal finding and there is clearly still room for improvement. There is still a range of barriers to accessing dental care. Perhaps the most difficult and resistant barrier is around extreme dental anxiety which affects 10\% of adults. Extreme dental fear is associated with irregular attendance together with potentially higher need, which remains an area of clinical concern.
This study was commissioned by the NHS Information Centre for Health and Social Care and was conducted on behalf of the Department of Health in England, the Welsh Assembly Health Department and the Department of Health, Social Services and Public Safety in Northern Ireland. The Survey was managed by the Office for National Statistics with a major contribution from The National Centre for Social Research. We would like to thank all of the specialists and colleagues who contributed from both organisations and also Dr Nigel Nuttall who has made such a huge contribution to the questionnaire element of the national survey series over the last 15 years. Our thanks also go to the field teams of dentists and recorders who undertook the examinations and interviews around the country, whose enthusiasm and work ethic often extended beyond the call of duty. Not least we are grateful to the 11,380 individuals who gave their time as survey participants.

Adult Dental Health Survey 2009 - The Health and Social Care Information Centre, Leeds.

Copyright ${ }^{\circ} 2011$, Re-used with the permission of the Health and Social Care Information Centre. A rights reserved.

1. National Instute of Clincal Excellence. Dental recall - recall intervals between routine dental examinations. Clinical guideline no. 19. London: NICE, 2004

2. Gray P G. Todd J E, Slack, G L B Bulman J S. Adult dental health in England and Wales in 1968. London: HMSO, 1970.

3. Finch H, Keegan, J, Ward K, Sanyal Sen B. Barriers to the receipt of dental care: a qualitative research study. London: Social and Community Planning Research, 1988.

4. Adams E K, Freeman R, Gelbier S. Accessing primary dental care in three inner city boroughs. Community Dent Health 1997; 14: 108-112.
5. Hill K B, White D A, Morris A J, Hall A C, Goodwin $N$, Burke F J. National evaluation of personal dental services: a qualitative investigation into patients' perceptions of dental services. Br Dent J 2003; 195: 654-658.

6. Cohen LK. Converting unmet need for care to effective demand. Int Dent J 1987: 37: 114-116.

7. Berkman L F, Glass T, Brissette I, Seeman T E. From social integration to health: Durkheim in the new millennium. Soc Sci Med 2000; 51: 843-857.

8. Vassend O. Anxiety, pain and discomfort associated with dental treatment. Behav Res Ther 1993: 31: 659-666.

9. Humphris G M, Morrison T, Lindsay S J. The Modified Dental Anxiety Scale: validation and United Kingdom norms. Community Dent Health 1995; 12: 143-150.

10. Schuller A A, Willumsen T, Holst D. Are there differences in oral health and oral health behaviour between individuals with high and low dental fear? Community Dent Oral Epidemiol 2003; 31: 116-121.

11. Armfield J M, Slade G D, Spencer A J. Dental fear and adult oral health in Australia. Community Dent Oral Epidemiol 2009; 37: 220-230.

12. Steele J G, Treasure E T, O'Sullivan I, Morris J, Murray J J. Adult Dental Health Survey 2009: transformations in British oral health 1968-2009. Br Dent J 2012; 213: 523-527.

13 White D A, Tsakos G, Piits N B, Fuller E, Douglas G V A, Murray J J, Steele J G. Adult Dental Health Survey 2009: common oral health conditions and their impact on the population. Br Dent J 2012; 213: 567-572

14. Corah N L, Gale E N, Illig S J. Assessment of a dental anxiety scale. J Am Dent Assoc 1978; 97: 816-819.

15. Krall E A, Dietrich T, Nunn M E, Garcia R I. 2006. Risk of tooth loss after cigarette smoking cessation. Prev Chronic Dis 2006; 3: A115. 